\title{
As especialidades convenientes à educação de mulheres no Brasil (séculos XIX e XX)
}

\author{
Specialties suitable for the education of women in
} Brazil (19th and 20th centuries)

Especialidades adecuadas para la educación de mujeres en Brasil (siglos XIX y XX)

MARTA MARIA DE ARAúJOiDa

CRISTINA COIMBRA VIEIRA (D $b$

\section{Resumo}

Com o propósito de refletir sobre os ofícios convenientes à educação de mulheres e sobre os fundamentos sociais e pedagógicos dessa educação, analisam-se dez artigos, publicados na Revista Educação em Questão (1987-2019), referentes à proposta deste estudo e circunscritos aos séculos XIX e XX no Brasil. A abordagem foi pautada pela orientação metodológica de Charlot (2006) quanto às dimensões indissociáveis da formação humana, da autoformação, da socialização e das singularidades na realidade do processo educacional, particularmente no domínio da história da educação de mulheres. Os artigos e a entrevista analisados revelam que, sem dúvida, as professoras eram as especialistas nos ofícios de ensinar e de educar diversificadamente. Nessa direção pedagógica, as dimensões indissociáveis da formação humana, da autoformação, da socialização e das singularidades da educação de mulheres, simultaneamente, reforçavam-se nas inequívocas especializações femininas circunscritas nos ofícios da realidade do processo educacional e das modalidades escolares, educação doméstica, colegial, coletiva de natureza pública, aulas particulares e pesquisas educacionais, tencionadas pela organicidade da divisão do trabalho e, igualmente, pelos fins determinantes das relações sociais.

Palavras-chave: Educação de mulheres. Especializações femininas. Divisão social do trabalho.

\footnotetext{
a Universidade Federal do Rio Grande do Norte (UFRN), Natal, RN, Brasil. Doutora em Educação, e-mail: martaujo@uol.com.br

b Universidade de Coimbra (UC), Coimbra, Portugal. Doutora em Ciências da Educação Psicologia da Educação, e-mail: vieira@fpce.uc.pt
} 


\begin{abstract}
With the purpose of reflecting on the convenient work occupations for the education of women and on the social and pedagogical foundations of that education, ten articles, published in the Revista Educação em Questão [Education in Question Journal] (19872019), referring to the proposal of this study and circumscribed to $19^{\text {th }}$ and $20^{\text {th }}$ centuries in Brazil, are analyzed. The approach was guided by Charlot's (2006) methodological orientation regarding the inseparable dimensions of human formation, self-formation, socialization and singularities in the reality of the educational process, particularly in the field of the history of women's education. The articles and the interview analyzed reveal that, without a doubt, the female teachers were the specialists in the professions of teaching and educating in a diversifying way. In this pedagogical direction, the inseparable dimensions of human formation, self-education, socialization and the singularities of women's education, simultaneously, were reinforced in the unequivocal female specializations circumscribed in the work occupations of the reality of the educational process and school modalities, domestic education, school education, collective of a public nature, private lessons and educational research, intended by the organicity of the division of labor and, equally, by the determinant ends of social relations.
\end{abstract}

Keywords: Women's education. (Self)Formation. Women's specializations. Social division of labor.

\title{
Resumen
}

Con el propósito de reflexionar sobre los oficios convenientes para la educación de las mujeres y sobre los fundamentos sociales y pedagógicos de esta educación, se analizan diez artículos, publicados en la Revista Educação em Questão [Revista Educación en Cuestión] (1987-2019), que hacen referencia a la propuesta de este estudio y se circunscriben durante siglos XIX y XX en Brasil. El enfoque fue guiado por la orientación metodológica de Charlot (2006) con respecto a las dimensiones inseparables de la formación humana, la auto formación, la socialización y las singularidades en la realidad del proceso educativo, particularmente en el campo de la historia de la educación de las mujeres. Los artículos y la entrevista analizados revelan que, sin duda, las profesoras eran especialistas en las profesiones de enseñanza y educación de manera diversa. En esta dirección pedagógica, las dimensiones inseparables de la formación humana, la autoformación, la socialización y las singularidades de la educación de las mujeres, simultáneamente, se reforzaron en las inequívocas especializaciones femeninas circunscritas en los oficios de la realidad del proceso educativo y las modalidades escolares, la educación doméstica, escolar, colectiva de carácter público, lecciones privadas e investigación educativa, concebidas por la organicidad de la división del trabajo e, igualmente, por los fines determinantes de las relaciones sociales.

Palabras clave: Educación de la mujer. (Auto)Formación. Especializaciones de mujeres. División social del trabajo. 


\section{Introdução}

Historicamente, a educação, a formação, a autoformação, as sociabilidades e a instituição educativa sempre definiram seus propósitos pedagógicos em cada época, sintonizando-os com o contexto social e a ordem cultural.

Em artigo de título "Formação humana na perspectiva histórico-ontológica", os pesquisadores Dermeval e Duarte estabelecem uma correlação entre formação humana e promoção humana, efetivada pela educação. Para Saviani e Duarte (2010, p. 431), a educação, nessa acepção, coincide com “[...] o processo por meio do qual se constitui em cada indivíduo a universalidade própria do gênero humano”. A formação humana que se promove pela educação sistematizada na instituição de ensino é, historicamente, alicerçada pelas sociabilidades escolares.

Por sua vez, o pesquisador Bernard Charlot (2006) chama a atenção para os estudos acerca da educação, que devem examinar aquilo que lhe é necessariamente próprio: as dimensões indissociáveis da formação humana, da socialização e das singularidades. Conforme Charlot (2006), essas dimensões humanas e de socialização (observando as peculiaridades do conjunto das ciências da educação) são uma frente de pesquisa que vai se constituir numa memória educacional, com suas variações de formulações metodológicas e empíricas, como deve ser todo conhecimento acadêmico e científico.

Considerando a orientação metodológica de Charlot (2006) quanto às dimensões indissociáveis da formação humana, da socialização e das singularidades da autoformação na realidade do processo educacional, o presente trabalho centrase na reflexão acerca da educação de mulheres nos séculos XIX e XX no Brasil, combinada com as consentâneas especialidades de ofícios a elas destinados e os seus fundamentos sociais e pedagógicos.

O corpus documental é composto por uma entrevista e nove artigos $(1,5 \%)$, do total de 601 pesquisados em 64 edições da Revista Educação em Questão (19872019), do Centro de Educação e do Programa de Pós-Graduação em Educação da Universidade Federal do Rio Grande do Norte. Desde a primeira edição (jan./jun. 1987), a Revista Educação em Questão constituiu-se com o devido propósito de 
divulgar a produção científica na área de Educação. Nesses 33 anos de existência a Revista Educação em Questão voltada para a importância da educação naquilo que lhe é específico e também geral, bem como dos resultados das pesquisas sobre a própria educação — vem renovando o propósito de publicar artigos inéditos de Educação, resultantes de pesquisa científica, além de resenhas de livros e documentos históricos.

Por sua vez, a entrevista e nove artigos referidos foram agrupados em duas categorias analíticas: a dimensão da formação humana na realidade do processo educacional de mulheres e a dimensão da formação humana de mulheres educadoras e pesquisadoras. A primeira, concernente às modalidades educacionais, todavia, é revelada pelas formas distintivas de ensinar às mulheres que, por precedência dos encargos futuros, situam-se na amplitude da formação e da autoformação, levada a efeito por preceptoras, professoras e educadoras. A segunda, referente às especializações do trabalho docente universitário na contingência das particularidades das atividades educativas exercitadas por mulheres professoras e pesquisadoras, é compreendida no justo meio, entre a formação acadêmica científica e a autoformação, como autorrealização da vida em profissão de educar mediante rituais coletivos, públicos, comunitários.

Este trabalho é um dos produtos do Projeto de Pesquisa Interinstitucional Educação de Mulheres ao Longo do Século XIX e XX (em desenvolvimento), voltado para uma história social de mulheres nesses dois séculos, no Brasil e em Portugal, pautada por influências sociais e políticas diversas.

\section{Dimensão da formação na realidade do processo educacional}

Nessa categoria analítica circunscrevem-se seis artigos que evidenciam as assimétricas distinções acerca da educação de mulheres em reciprocidade com as modalidades escolares, discutidas de conformidade com a época histórica.

\section{Princesas Isabel e Leopoldina Modalidade Educação Doméstica}


As cartas e os bilhetes das Princesas Isabel e Leopoldina, principalmente para seus pais (o Imperador Dom Pedro II e a Imperatriz Dona Teresa Cristina), no período de 1850 a 1864, constituíram a matéria prima, por excelência, da pesquisa de Jaqueline Vieira de Aguiar e Maria Celi Chaves Vasconcelos (2012), para a recomposição da socialização escolar e da formação propiciada às herdeiras do Trono e da Coroa do Brasil. As historiadoras da educação, Aguiar e Vasconcelos, ao tratarem dos motivos da constância das trocas de cartas e bilhetes entre as princesas e seus pais, assim esclareceram:

A troca de cartas e bilhetes era o meio utilizado pelas princesas Isabel e Leopoldina para se comunicar com os pais. A utilização desse recurso fazia-se necessária, pois a distância entre eles ocorria por vários motivos. Quando os Imperadores viajavam, também procuravam enviar correspondências às filhas para se informar sobre o estado de saúde das meninas e sobre as lições recebidas diariamente por elas. Tal fato fica bastante evidente nas cartas escritas por D. Pedro II às Princesas, no período em que os Imperadores visitaram as províncias do Norte (AGUIAR; VASCONCELOS, 2012, p. 14).

As preceptoras titulares e auxiliares das Princesas Isabel e Leopoldina, escolhidas por Dom Pedro II, foram Luíza Margarida de Barros (Condessa de Barral de 1856-1864) e Mademoiselle Victorine Templier (1857-1864). Na modalidade escolar educação doméstica, a Condessa de Barral dedicou-se, acima de tudo, à educação de Isabel (princesa Imperial); à dama francesa, cabia responsabilizar-se pela educação de Leopoldina.

Pelas cartas, bilhetes e outros documentos analisados (Atribuições da Aia, escritas por Dom Pedro II e Dona Teresa Cristina, por exemplo), a formação das Princesas Isabel e Leopoldina, ao longo de quatorze anos, nessa modalidade escolar educação doméstica, por um lado, requereu um conjunto extensivo de matérias estudadas (Escritura, Leitura Portuguesa e Francesa, Retórica, Ortografia, Literatura Portuguesa, Estilo em Português e em Francês, Alemão, Latim, Grego, Poesia Portuguesa, História da França, História da Inglaterra, História da América, História Santa, História Antiga, História do Consulado e Império, Economia Política, Piano, Desenho e Pintura); por outro lado, demandou a quantidade de 25 mestres, sendo 22 homens e 3 mulheres. Esta desigualdade no número de educadores e de educadoras não deixa de ser curiosa e retrata também a organização social da época, como descreveu Cristina C. Vieira (2002), no que concerne a quem detinha o 
conhecimento científico que ensinava às gerações mais novas e também ao tipo de ensinamentos que convinham às mulheres.

No tocante às mestras e aos mestres das Princesas Isabel e Leopoldina e de alguns procedimentos de avaliação das aprendizagens, as autoras ressaltaram o seguinte:

[Dentre as mestras], duas eram a preceptora, a auxiliar e ainda Madame Diémer. Entre os 25 professores, 5 já haviam atuado como mestres de D. Pedro II e de suas irmãs anos atrás [...]. Isabel e Leopoldina eram constantemente avaliadas pelos mestres, pela preceptora e até por seus médicos. As Princesas enviavam aos pais, por meio de cartas, as notas obtidas, e igualmente a preceptora comunicava aos Imperadores as notas e 0 comportamento moral de suas discípulas (AGUIAR; VASCONCELOS, 2012, p. 27).

De qualquer ângulo que se observe a formação das princesas Isabel e Leopoldina, propiciada por seus pais, mediante a modalidade escolar educação doméstica, esta se mostra em sintonia com as exigências de uma formação e uma autoformação condizentes com prováveis encargos, que lhes poderiam sobrevir no caso de assumirem o governo do Trono do Brasil. Havia uma preocupação não apenas com as notas escolares, mas também com a saúde e os valores e princípios que norteavam a conduta das princesas, numa visão que diríamos integral do desenvolvimento humano, na transição para a vida adulta.

As duas futuras soberanas casaram-se, respectivamente, em 1864, ano do término dos estudos formativos e autoformativos. A Princesa Isabel (com 16 anos) casou-se com o Príncipe francês Luís Felipe Maria Fernando Gastão de Orléans, Conde d'Eu. A Princesa Leopoldina (com 17 anos) casou-se com Luís Augusto Maria Eudes, Duque de Saxe-Coburgo-Gotha, natural da Áustria.

\section{Viscondessa de Arcozelo Modalidade Educação Doméstica}

Analisando o Diário de Lembranças, escrito pela Viscondessa de Arcozelo (Maria Isabel de Lacerda Werneck), no ano de 1887, Maria Celi Chaves Vasconcelos (2015) ressalta como uma das múltiplas leituras, a ser depreendida, a condição social feminina da autora e a educação demonstrada, tanto no hábito cultivado de escrever 
um diário íntimo quanto na formação e na autoformação, voltadas para o desempenho de um ofício, almejado por uma mulher nobre.

A educação da Viscondessa de Arcozelo, segundo os padrões das elites para educar filhas e filhos, teria sido pautada pela modalidade escolar educação doméstica (como era então comum), ficando a cargo de uma preceptora estrangeira, que era mais capacitada para educar e socializar ensinamentos de conformidade com modelos europeus para mulheres - a educação completa. Para Vasconcelos, a habitual educação completa feminina das elites oitocentistas geralmente compreendia “[...] o ensino da escrita, leitura e contas (para a contabilidade doméstica), ensinamentos de português e francês prioritariamente, seguidos de caligrafia, literatura, composição, religião, música, piano, solfejo, canto, gramática portuguesa, latina e francesa" (VASCONCELOS, 2015, p. 122).

Casada em 1860 (aos vinte anos de idade) com o médico português das fazendas de café de seu pai, Joaquim Teixeira de Castro, a Viscondessa de Arcozelo contratou, para a educação dos seus filhos homens (não teve filhas mulheres) como era de costume pela modalidade escolar doméstica —, uma preceptora portuguesa, (D. Sarah), que permaneceu com a família por bem pouco tempo. Isso devido ao fato de o Visconde haver decidido dispensar seus serviços para mandar os seus filhos estudarem num colégio de elite, além dos limites da educação doméstica. Concernente à essa mudança de mentalidade das famílias nobres, Vasconcelos, assim, se expressa:

Com o crescimento do número de colégios que ocorre, nas últimas década do século XIX, acaba por seduzir as elites para uma possibilidade de educação coletiva que, fora da casa, segundo seus propagandistas, permitiria a formação dos sujeitos para enfrentar os desafios do século XX, que se anunciava [...]. Ou seja, sem muita clareza, já se supunha que algo estava para mudar também nas relações educacionais. Em um mundo que se transformava em diferentes aspectos, e a educação era um deles, conjeturava-se que, brevemente, poderia se estabelecer a hegemonia da escola [...] (VASCONCELOS, 2015, p. 125).

Discutir a educação escolar de modalidade doméstica e os ensinamentos socializados por meio da Viscondessa de Arcozelo, fez com que Vasconcelos (2015) refletisse acerca dos modos de educar e das formas de socializar ensinamentos que, historicamente, eram correlatos com as maneiras de viver de uma elite nobre no século XIX. A educação doméstica da Viscondessa de Arcozelo, conforme as suas 
anotações no Diário de Lembranças, revela aos leitores do século XXI traços distintivos da formação e da autoformação de uma mulher nobre, as quais se traduziam na capacidade de ser boa mãe, gestora competente da casa e, até certo ponto, dotada do ofício de administradora dos negócios familiares. Esta visão menorizante da importância da educação para as mulheres, mesmo para as de classes superiores, foi destacada por Elisabeth Badinter, numa obra publicada em 1980, quando defendeu que o desenvolvimento da inteligência das mulheres era visto, ainda durante o século XIX, como fundamental, sobretudo para o adequado desempenho das funções da maternidade e como garantia de longevidade do matrimónio. Além disso, ainda segundo a autora, os ideólogos dessa época consideravam que a educação traria também benefícios para as mulheres, auxiliando-as a controlar as alegadas fraquezas do corpo e do espírito femininos.

\section{Educação de mulheres de elite Modalidade Educação Doméstica e Colegial}

Foi no plano de uma rede diversificada de escolas femininas privadas (colégios e aulas particulares), que Maciel e Peres (2007) pesquisaram, em jornais de circulação diária da cidade de Pelotas (Rio Grande Sul), no período de 1875-1890, a educação feminina e a formação análoga proporcionada por essa rede de instituições privadas.

Na pujante cidade de Pelotas, no período referido, nos colégios femininos, a educação das alunas provinha da socialização do ensino propedêutico por meio de matérias de estudo diretamente relacionadas com uma formação humanista (português, leitura, caligrafia, francês, inglês, música, geografia, história), além de uma formação instrutiva (aritmética, desenho, contabilidade escrita, trabalhos de costura, bordados, pontos de agulha). A formação humanista e instrutiva, propiciada pelos colégios femininos privados, subentendia uma acepção de vida moderna urbana, civilizada, bem como, indispensavelmente, uma autoformação.

Educação, [formação] e instrução feminina para a elite reuniam [...] as habilidades de leitura, oralidade e o domínio de diversas línguas para bem acompanhar e representar na sociedade seu marido; e os conhecimentos científicos vinculados à modernização e civilização da sociedade (MACIEL; PERES, 2007, p. 57). 
A expectativa de uma unidade de formação humanista e instrutiva para a educação feminina na cidade de Pelotas desdobraria na modalidade escolar de aulas particulares, ministradas na residência da professora ou no domicílio da aluna, além de aulas ministradas por preceptoras que residiam nas casas de famílias da elite local. Pelos anúncios pesquisados, essas professoras e preceptoras brasileiras e estrangeiras lecionavam, em moldes individualizados, as matérias língua portuguesa, língua francesa, língua italiana, língua inglesa, língua alemã, piano, música e trabalhos de agulha. Certos anúncios pesquisados chegavam a chamar a atenção pelo conteúdo veiculado, como revelam as autoras, que assim se pronunciam:

Um número significativo de professoras, principalmente as estrangeiras, fundaram colégios femininos ou atuavam paralelamente em ambos os espaços. As aulas particulares foram, nesse sentido, uma estratégia que algumas professoras utilizaram para estabelecerem-se e investirem em um projeto mais ambicioso: a criação e a manutenção de uma escola (MACIEL; PERES, 2007, p. 51, grifo das autoras).

No século XIX, em Pelotas, as escolas femininas privadas (nos regimes de colégios) e as aulas particulares organizadas de conformidade com o binômio educação coletiva, formação humanista e instrutiva individual, além da autoformação, voltaram-se para as distinções de ofícios nas situações da vida privada familiar e da vida pública das mulheres de elite.

\section{Educação de mulheres Modalidade Educação Colegial e Coletiva}

Conforme registra a história da educação no Brasil, na transição do século XIX para o século XX, a inserção da mulher na sociedade letrada desencadeou inúmeras matérias em jornais sobre a educação feminina. Um desses jornais, a República, fundado em 1889, na capital do Rio Grande do Norte (Natal), pelo médico e político Pedro Velho de Albuquerque Maranhão, foi objeto de pesquisa de Pinheiro e de Morais (2008), que investigaram a educação feminina no período de 1898-1910. 
As matérias sobre educação feminina, escritas no Jornal a República, concebiam a função social da mulher como sendo educadora da família e da sociedade. Nesse sentido, os colégios femininos privados seriam a instituição cultural necessária à formação e à autoformação das mulheres de elite, visando exercer essa dupla função social. Conforme Pinheiro e Morais (2008), algumas das matérias sobre a educação feminina alinhavam-se à defesa do aumento quantitativo dessa instituição cultural para a inserção da mulher na sociedade do trabalho com as suas divisões de ofícios.

Ao defender a educação feminina e a institucionalização dessa educação pelas escolas, é perceptível [nas matérias] a sintonia entre um discurso sobre o sentido de ser cidadão e uma instrução que pretendia um modelo de mulher, de família e de sociedade (PINHEIRO; MORAIS, 2008, p. 65).

A educação feminina devia, necessariamente, segundo Pinheiro e Morais (2008, p. 65), “[...] destinar às moças, os conteúdos instrucionais da música, das línguas estrangeiras e as habilidades domésticas, formando-as, educando-as". No ano de 1894, por exemplo, o Colégio Nossa Senhora da Apresentação, com sede em Natal, destinado à educação feminina de mulheres de elite, anunciava, no Jornal A República, o seu programa de estudo: Português, Francês, Alemão, Aritmética, Princípios da Geometria, Desenho, História, Geografia, Música, Piano e Trabalhos Manuais. No parecer das autoras, a educação feminina na transição entre os séculos XIX e XX em Natal, principalmente,

[...] trazia o programa de estudo impregnado com o perfume da modernidade, da República e de uma representação de mulher e do seu entorno social. A educação da mulher estava representada também nas manifestações artísticas e literárias desse entre século (PINHEIRO; MORAIS, 2008, p. 69).

Assumindo a defesa da educação feminina para as funções sociais de educar e de ensinar, o Jornal A República promovia, pelas matérias que veiculava, a percepção em torno de uma formação e autoformação integral para as mulheres, compreendendo a socialização de ensinamentos dirigidos à elegância, aos bons costumes, às virtudes humanas, ao patriotismo republicano e aos ofícios femininos. Notadamente, os colégios femininos (privados) cresciam em quantidade com seus programas de estudos complexos, diversificados, diferenciados e elitistas, tomando a seu encargo a educação feminina do Rio Grande do Norte. 


\section{Mulheres professoras de crianças Modalidade Escolar Coletiva e Especializada}

Ao analisar as memórias de formação de quatro professoras de crianças, nascidas nas décadas de 1940 e 1950, em cidades de porte médio do interior do Estado de São Paulo, Almeida (2006, p. 88-89), a princípio, torna patente que a educação escolar, em geral, era percebida como prolongamento do lar, que preservava, até certo ponto, muitos dos ensinamentos das práticas culturais, socializadas na família "[...] como a ordem social, a submissão, o bom comportamento, o respeito aos mais velhos e à autoridade”.

As Escolas Normais onde estudaram as professoras da pesquisa de Almeida eram por elas lembradas como promotoras de “[...] cursos de formação de professores de qualidade, que empregavam bons métodos de ensino, possuíam excelentes programas e tinham ótimos professores”. Para Almeida (2006), é inegável que, nas décadas de 1940 e 1950, as Escolas Normais eram a instituição, por excelência, especializada na veiculação de modernos métodos de ensinar crianças e das mais avançadas concepções pedagógicas de educar.

Se as lembranças dos cursos de qualidade acadêmica das Escolas Normais enalteciam os métodos de ensinar crianças, o programa de estudo socializado e o nível de excelência dos seus professores, era justamente porque a eficácia da formação e da autoformação especializada para o magistério estava essencialmente vinculada ao ato de "[...] gostar de crianças, ao amor à profissão e à conduta pessoal [...] não desvinculada da competência técnica necessária para o exercício profissional" (ALMEIDA, 2006, p. 89).

De fato, nas narrativas das professoras paulistas, o discurso da eficiência dos cursos normalistas (representados pela pedagogia da Escola Nova) alinhava-se com o discurso da eficácia da formação especializada (sentimento de amor, de afeto, de solidariedade, de vocação profissional). Conforme Almeida (2006), a formação e a autoformação pedagógica, para o magistério dessas professoras paulistas, incluíam uma cultura geral e especializada, didática e técnica, para o exercício da profissão de professoras de crianças, tida e havida como digna e de alto conceito social. 


\section{Educação de mulheres negras Modalidade Escola Coletiva}

A história da educação de mulheres no Brasil é estudada por meio de uma pluralidade de ângulos de pesquisa. Um desses ângulos contempla a história da educação de mulheres negras, reconstituída por Almeida e Alves (2011), de conformidade com a metodologia da história oral. As dez mulheres negras participantes da aludida pesquisa viveram a sua infância e juventude entre 1950 e 1970, na cidade de Juiz de Fora (Minas Gerais).

Em primeiro lugar, vale considerar o fato de que a educação de mulheres negras, de maneira geral, é inegavelmente associada, por elas mesmas, a interrupções e impedimentos sociais. Conforme Almeida e Alves (2011, p. 87), as mulheres negras que tiveram acesso à escolarização primária, principalmente na década de 1950, encontraram na instituição escolar pública, principalmente, “[...] um ambiente hostil a tudo aquilo que se caracterizava a sua existência: seus modos de vida, sua linguagem, sua cor, seu cabelo, seus cultos".

Em segundo lugar, o ingresso e a permanência dessas mulheres negras, na escola pública primária, foram “[...] investidos de um caráter de travessia insalubre, em que a menina negra nunca se via contemplada nos elementos da cultura escolar com as quais convivia" (ALMEIDA; ALVES, 2011, p. 94).

Em terceiro lugar, o acesso ao ensino médio (secundário ou profissional), por parte dessas mulheres negras, revela-se, nas suas memórias, como sendo árduo, demorado e marcado por interrupções para algumas delas, ou tida como inviáveis para outras. Seguramente, para Almeida e Alves (2011), na história restrita da educação dessas mulheres negras, a instituição escolar (geralmente pública) desponta como socialmente decisiva, tanto no que concerne à oferta limitada de vagas (destinada, apenas, para aquela juventude de uma condição social mais ou menos privilegiada) quanto no que diz respeito à discriminação racial — fosse pela aceitação de um não lugar social para as mulheres negras, fosse pela negação sistêmica do direito de estudar. 


\section{As Mulheres educadoras e a formação especializada}

Nessa categoria analítica situam-se 3 artigos, concentrados nas mulheres educadoras em reciprocidade com os ofícios gerais, as especializações e o trabalho intelectual, que são apresentados pela época histórica da docência e da produção intelectual.

\section{Caroline Tamplin Educação completa e especializada}

A britânica Caroline Tamplin, que viveu na Província do Paraná (Turvo, um dos núcleos da colônia do Assungui, próximo de Curitiba, de 1868 a 1888), era professora de filhos de imigrantes de diversas nacionalidades e de brasileiros em uma escola estabelecida na sua fazenda (The Grange, de 1874-1880). Com base nos registros do seu diário íntimo, que se insere no gênero de escrita autobiográfica, Gillies (2017) descreve, assim, a educação completa dessa professora no plano cultural, formal e intelectual:

A educação dos modos para aquisição de boas maneiras, a educação formal, recebida na escola ou em casa com tutores, e a educação intelectual, por intermédio do cultivo de si pela leitura e pelo aprendizado de outros idiomas compuseram os sinais de sua distinção (GILLIES, 2017, p. 66).

Com a qualificação de educação completa e de educação permanente de caráter geral e especializada, Gillies (2017, p. 67) referia-se tanto às habilidades da professora Caroline Tamplin para o trabalho docente quanto à sua vasta formação e autoformação cultural, compreendendo “"...] um roll de habilidades apropriadas para as sociabilidades". Entre essas sociabilidades, destacava-se a sua especialização artística de tocar piano em soirées, principalmente aqueles que homenageavam autoridades da Corte, a exemplo da Princesa Isabel e do Conde d'Eu, quando estiveram, em dezembro de 1888, visitando a capital da Província do Paraná.

Obviamente, para Gillies, a pesquisa, no diário da imigrante inglesa Caroline Tamplin, foi o que tornou possível a produção de um conhecimento da história da 
educação no século XIX no Brasil, em que se equiparavam a educação completa e a educação permanente de caráter geral e a especializada, as sociabilidades culturais, artísticas e escolares e a escrita autobiográfica feminina de uma professora de crianças.

\section{Cecília Meireles}

\section{Educação completa e formação especializada}

A intelectual Cecília Meireles (1901-1964) é uma referência de educadora, para Araújo (2001-2003), devido ao fato de, fundamentada no ideário da Escola Nova, haver debatido, com profundidade, o sentido humano, social e político do ato de educar e ensinar, especialmente na "Página de Educação" do Diário de Notícias do Rio de Janeiro (1930-1933). Conforme Araújo (2001-2003, p. 11), antes de tudo, o ato de educar e ensinar, para Cecília Meireles, havia de ser "[...] por uma educação renovadora e para todos, como instrumento prioritário de correção das desigualdades sociais brasileiras". Por sua vez, a educação, como arte de vida e de formação, e de autoformação hábil para um ofício, era o primeiro fundamento humano de uma pátria e de um povo.

\section{Maria Isaura de Medeiros Pinheiro Educação completa e formação especializada}

A historiadora Maria Isaura de Medeiros Pinheiro (nascida em Natal e formada em Direito pela Faculdade de Direito do Recife e em História pela Faculdade de Filosofia Ciências e Letras de Natal), professora e pesquisadora do Departamento de Educação da Universidade Federal do Rio Grande do Norte (1965 a 1990, período em que exerceu os cargos de Vice-Diretora da Faculdade de Filosofia Ciências e Letras, Vice-Coordenadora do Curso de Pedagogia, Chefe do Departamento de Educação e Pró-Reitora de Graduação), respondeu a uma entrevista sobre a sua educação escolar, a sua formação e autoformação ao logo da vida, cujas perguntas foram elaboradas pelas professoras Marta Maria de Araújo e Maria Estela Costa Holanda Campelo. 
Segundo a professora Maria Isaura, sua primeira educação escolar formal foi iniciada no $3^{\circ}$ ano primário no Colégio Nossa Senhora das Neves de Natal. Aprender qualquer que fosse a matéria significava, à época, memorizar os conteúdos estudados: "O hábito de memorizar havia se tornado tão dominante que inclusive era praticada no ensino de História” (PINHEIRO, 2004, p. 143).

Em se tratando do curso ginasial e do curso clássico no Ateneu NorteRiograndense de Natal, a prof. a Maria Isaura (2004, p. 143), relembra que "[...] os seus professores tinham uma espécie de compromisso bem maior com o próprio saber que dominavam do que com [aquilo] que os alunos viessem apreender". Enfim, a proposta pedagógica era bem mais a transmissão dos conhecimentos culturais.

A docência universitária da prof. a Maria Isaura, no curso de Pedagogia da Faculdade de Filosofia Ciências e Letras (vinculada à Fundação José Augusto), teve início no ano de 1965, lecionando as disciplinas de Filosofia da Educação, de História da Educação e de Educação Comparada. Em sua percepção, a disciplina Educação Comparada, especificamente, “[...] abria-se para estabelecer elos com a História de diversos países, o que tornava o estudo bem estimulante para os alunos" (PINHEIRO, 2004, p. 145-146).

No curso de Pedagogia da Universidade Federal do Rio Grande do Norte, a prof. a Maria Isaura lecionou a disciplina Didática, na perspectiva da chamada Escola Nova, cujos fundamentos e a destinação formativa da chamada "Didática Nova" são assim descritos:

A Psicologia através de princípios como da valorização do educando, atendia aos seus interesses e respeito a sua individualidade formativa, indicava um dos fundamentos da Didática Nova. Enquanto a escola era vista na perspectiva da socialização do educando (PINHEIRO, 2004, p. 146).

É certo que a formação e a autoformação continuada da prof. ${ }^{a}$ Maria Isaura foram proveniente de suas especializações no plano da prática docente. Sua convicção, no entanto, sinaliza no sentido de que essas especializações são resultantes de redimensionamentos sistemáticos “[...] motivados por leituras críticas e pelo próprio contexto educacional que se alterava e que conduzia a um pleno 
convencimento para tanto" (PINHEIRO, 2004, p. 150). Analisando-se sob essa ótica, pode-se dizer que a sua educação e a sua formação geral e especializada, ao longo da vida, estão intimamente vinculadas à sua autoformação ao seu incontido desejo de querer sempre aprender e de socializar o que aprendeu com afeto pedagógico.

Iria Brzezinski Educadora e pesquisadora de formação de professores

Em história de vida: como me tornei pesquisadora?, Iria Brzezinski (2006) reconstitui a sua história de vida como professora e pesquisadora da área de educação e de formação, que assim sintetiza:

Ao longo da minha formação e construção da carreira de pesquisadora, tive a rara oportunidade de viver a minha condição humana dedicando-me aos estudos individualmente, ao mesmo tempo em que respeitava pesquisadores mais experientes, que me auxiliavam na descoberta de pista da investigação da formação (BRZEZINSKI, 2006, p. 192).

A professora e pesquisadora Brzezinski (2006) compreende que as suas pesquisas específicas sobre a formação de profissionais da educação no curso de Pedagogia, que coincidem com sua militância nos movimentos de educadores (1980 e 1990) e com os avanços tecnológicos e mudanças de paradigmas da ciência. Por conseguinte, levaram-na pela experiência de pesquisa coletiva, a buscar alternativas de mudanças para os cursos de formação, passando pelas instituições de ensino superior, as universidades e as agências contratantes até os órgãos do aparelho de Estado. Notadamente, os movimentos de educadores que é participante elevam-se, para Brzezinski, como

[...] verdadeiros locus de fecundidade de ideias que atualizam os profissionais da educação, colocando-os na contemporaneidade da produção científica. Esta modalidade de formação contínua promovida pelo movimento dos educadores, entre outros aspectos, permite desvelar algumas estratégias por onde enveredam as decisões políticas sobre o preparo e valorização dos profissionais da educação e fortalece (BRZEZINSKI, 2006, p. 198).

Enfim, tudo isso foi devido à especialidade de articular, pela pesquisa individual ou em grupo e, igualmente, pelos movimentos de educadores, a formação 
e a autoformação de professores com a objetividade institucional e a subjetividade humana individual e coletiva.

\section{Conclusão}

O sociólogo francês Émile Durkheim (1978) observou, nos seus estudos, que não existe uma sociedade cujo sistema de educação seja heterogêneo e especializado, propiciado pela diversidade das profissões no curso da vida coletiva. Cada profissão — por exemplo, a de professor — reveste-se de dimensões sui generis que reclamam "[...] aptidões particulares e conhecimentos especiais, que [são] regidos por certas ideias, certos usos, certas maneiras de ver as coisas; e, como a criança deve ser preparada em vista de certa função, a que será chamada a preencher" (DURKHEIM, 1978, p. 39).

Nos termos de Durkheim (1978, p. 41), a educação é que assegura, mediante a socialização metódica das novas gerações, a persistência da heterogeneidade socialmente necessária “[...] diferenciando-se, ela própria, permitindo as especializações". Ora, para esse sociólogo, a vida humana e social depende da diversidade de aptidões profissionais correlatas com a formação humana conveniente à instituição educativa, às sociabilidades e ao sistema escolar.

É a sociedade que, para poder manter-se, tem necessidade de dividir o trabalho entre seus membros, e dividi-los de certo e determinado modo. [...] É, pois, por ela e para ela que a educação se diversifica. [...] São ideias e sentimentos coletivos o que ela exprime (DURKHEIM, 1978, p. 78 e 89).

Não obstante, ao discorrer sobre a divisão social do trabalho, Durkheim (2010) apresenta as especializações por ofícios decorrentes da educação, das relações intersociais, do trabalho científico, das regras jurídicas e dos arranjos profissionais, para além das sociedades, cada vez mais densas, crescentes, complexas. Também na percepção desse sociólogo, uma atividade social, educacional ou mesmo econômica torna-se especializada, "[quando] essa especialização corresponder a uma necessidade da sociedade. [...] Se nos especializamos, não é para produzir mais, e sim para podermos viver nas novas condições de existência que nos são criadas" (DURKHEIM, 2010, p. 270 e 274).

Esse sociólogo atenta para o fato de a divisão do trabalho, que é consequente das relações sociais, necessariamente preconizar a diversidade das 
especializações, qualitativamente equivalentes em circunstâncias profissionais dadas. Para Durkheim (2010, p. 6), a preponderância progressiva da divisão social do trabalho “[...] é o caráter cada vez mais especial que a educação adquire”.

A divisão social do trabalho presume, necessariamente, formar mulheres e homens para determinados ofícios especializados. Nessa medida, argumenta Durkheim (2010, p. 430): “A divisão do trabalho não põe em presença indivíduos, mas funções sociais". Nas palavras de Oliveira (2001), as funções sociais e o consequente acúmulo das especializações respondem por processos que percorrem os fundamentos da própria formação da sociedade de classe.

As dimensões indissociáveis da formação humana, da autoformação, da socialização e das singularidades da educação de mulheres nos séculos XIX e XX deixam explícitas as distintas especializações femininas, acumuladas nos ofícios da realidade do processo educacional (modalidades escolares educação doméstica, colegial, coletiva pública, aulas particulares, pesquisas educacionais especializadas). Tudo isso é tencionado pela organicidade da divisão do trabalho e, igualmente, pelos fins determinantes das relações sociais no domínio privado e na esfera pública e coletiva. A esse propósito, esclarecem Kuhlmann Junior e Leonardi:

[Há] a necessidade da compreensão de que os fenômenos educacionais são elementos constitutivos das relações sociais e se produzem no interior dessas relações e não à parte, ou sobrepostos a elas. São processos históricos em que as relações sociais definem grupos e setores sociais considerados como passíveis de serem educados. Se as concepções, as formas, as propostas educacionais são históricas, então a compreensão da sua história não poderia restringir-se aos limites escolares, isolando a educação das suas relações com o econômico, o geográfico, o social e o cultural (KUHLMANN JUNIOR; LEONARDI, 2017, p. 210).

As dimensões indissociáveis da formação humana, da autoformação da socialização e das singularidades na realidade do processo educacional no Brasil (séculos XIX e XX), combinadas com as especializações femininas - em última instância neste estudo —-, desencadearam a planificação dos pressupostos de uma uniformidade da reprodução das relações sociais. Ademais, desencadearam também os ofícios da divisão do trabalho docente e os fundamentos sociais e pedagógicos que organizavam os sistemas de ensino.

\section{Referências}


AGUiAR, J. V. de; VASCONCELOS, M. C. C. "Meus caros paes": A educação das Princesas Isabel e Leopoldina. Revista Educação em Questão, Natal, v. 44, n. 30, p. 6-35, set./dez. 2012.

ALMEIDA, G. E. de; ALVES, C. M. C. Educação escolar de mulheres negras: interdições históricas. Revista Educação em Questão, Natal, v. 41, n. 27, p. 81-106, jul./dez. 2011.

ALMEIDA, J. S. de. Memórias da educação: professoras primárias no interior paulista (1940-1950). Revista Educação em Questão, Natal, v. 27, n. 13, p. 77-96, set./dez. 2006.

ARAÚJO, M. M. de. Lembrando a educadora Cecília Meireles. Revista Educação em Questão, Natal, v. 14-18, n. 4, p. 10-17, jul./dez. 2001 a jul./dez. 2003.

BANDINTER, E. L'Amour en plous. Histoire de l'amour maternel (XVIIe-XXe siècle). Paris: Flammarion, 1980.

BRZEZINSKI, I. História de vida: como tornei-me pesquisadora? Revista Educação em Questão, Natal, v. 25, n. 11, p. 190-205, jan./abr. 2006.

CHARLOT, B. A pesquisa educacional entre conhecimentos, políticas e práticas: especificidades e desafios de uma área de saber. Revista Brasileira de Educação, Rio de Janeiro, v. 11, n. 31, p. 7-18, jan./abr. 2006.

DURKHEIM, É. Educação e sociologia. Trad. Lourenço Filho. 11. ed. São Paulo: Edições Melhoramento. Brasília: Fundação Nacional do Material Escolar, 1978.

DURKHEIM, É. Da divisão do trabalho social. Trad. Eduardo Brandão. São Paulo: Martins Fontes, 2010.

GILLIES, A. M. R. A educação no diário de uma imigrante britânica e em outros escritos na província do Paraná. Revista Educação em Questão, Natal, v. 55, n. 43, p. 51-73, jan./mar. 2017.

KUHLMANN JUNIOR; LEONARDI, M. P. História da educação no quadro das relações sociais. História da Educação, Porto Alegre, v. 21, n. 51, p. 207-227, jan./abr. 2017.

MACIEL, P. D; PERES, E. O ensino feminino privado em Pelotas no Rio Grande do Sul (século XIX). Revista Educaşão em Questão, Natal, v. 28, n. 14, p. 42-65, jan./jun. 2007.

OLIVEIRA, F. de. Intelectuais, conhecimento e espaço público. Revista Brasileira de Educação, Rio de Janeiro, n. 18, p. 125-132, set./dez. 2001.

PINHEIRO, M. I. de M. A formação da educadora e a educadora Maria Isaura de Medeiros Pinheiro. Revista Educação em Questão, Natal, v. 20, n. 6, p. 143-151, maio/ago. 2004. (Entrevista concedida para as professoras Marta Maria de Araújo e Maria Estela Costa Holanda Campelo).

PINHEIRO, R. K. B. de S; MORAIS, M. A. C. de. Educação para mulheres na transição do século XIX para o XX. Revista Educação em Questão, Natal, v. 31, n. 17, p. 53-72, jan./abr. 2008.

SAVIANI, D; DUARTE, N. A formação humana na perspectiva histórico-ontológica. Revista Brasileira de Educação, Rio de Janeiro, v. 15, n. 45, p. 422-433, set./dez. 2010. 
VASCONCELOS, M. C. C. Uma mulher educada no oitocentos: a escrita feminina no Diário da Viscondessa de Arcozelo. Revista Educação em Questão, Natal, v. 53, n. 39, p. 104131, set./dez. 2015.

VIEIRA, C. C. Em defesa do direito da mulher à educação: alguns apontamentos históricos. Revista Portuguesa de Pedagogia, Coimbra, v. 36, n. 1-3, p. 581-599, 2002.

RECEBIDO: 04/08/2020

APROVADO: 03/10/2020

RECEIVED: 08/04/2020

APPROVED: $10 / 03 / 2020$

RECIBIDO: 04/08/2020

APROBADO: 03/10/2020 